\title{
Fe- Containing lonic liquid Supported on Nanosized MCM-41: An Efficient and Reusable Catalyst in the Synthesis of 2-Aryl Benzimidazole Derivatives
}

\author{
ESMAT IZADPANAH ${ }^{1}$ and SOHEIL SAYYAHI ${ }^{2 *}$ \\ ${ }^{1}$ Department of Chemistry, Omidiyeh Branch, Islamic Azad University, Omidiyeh, Iran. \\ ${ }^{2}$ Department of Chemistry, Mahshahr Branch, Islamic Azad University, Mahshahr, Iran. \\ ${ }^{*}$ Corresponding author E-mail: sayyahi.soheil@gmail.com \\ http://dx.doi.org/10.13005/ojc/320438
}

(Received: June 26, 2016; Accepted: August 04, 2016)

\begin{abstract}
In this study, an efficient method for the synthesis of 2-Aryl Benzimidazole derivatives has been developed. The synthesis was performed by condensation aromatic benzaldehydes and 1.2 phenylenediamin using $[\mathrm{bmim}]\left[\mathrm{FeCl}_{4}\right] / \mathrm{MCM}-41$ as a heterogeneous catalyst under reflux conditions and at $60 \mathrm{C}$. The advantages of this method are easy work-up procedure, clean and neutral reaction conditions. The separation and reuse of the catalyst were simple and could be reused without a significant loss of catalytic activity. Moreover, the products were achieved in good yields (70-83\%).
\end{abstract}

Keywords: Magnetic ionic liquid, MCM-41, Banzimidazoles.

\section{INTRODUCTION}

Mesoporous silica nanoparticles with uniform pore size and a long-range ordered pore structure were first reported in the early 1990s using surfactants as structure-directing agents (SDAs). Now, rapid progress has been achieved in the synthesis and application of ordered MSNs in catalysis, adsorption, separation, sensing, and drug delivery ${ }^{1}$. Among the various types of mesoporous silica, MCM-41 exhibits a highly ordered hexagonal array of one dimensional mesoporous with a pore diameter of $15-100 \AA$, high surface area $\left(>1000 \mathrm{~m}^{2}\right.$ $\left.\mathrm{g}^{1}\right)$ and high thermal stability $\left(\mathrm{ca} .900^{\circ} \mathrm{C}\right)^{2}$.

Magnetic ionic liquids (MILs) ${ }^{3}$ incorporated with inorganic or organic paramagnetic ions are a new type of ionic materials having high ionic conductivity, magnetic responsiveness and sometimes integrated with luminescence activity 4 . 
The MILs are primarily based on highspin d5 Fe (III) in the form of tetrachloroor tetrabromoferrate(III) with various counter cations. Owing to the high single-ion magnetic moments, these MILs exhibited a strong response to magnetic fields ${ }^{5}$. Since then, much attention has been paid to the design and synthesis of this new class of ILs ${ }^{6-10}$. Moreover, the catalytic activities of MILs have been studied in Friedel Crafts acylation ${ }^{11}$, aryl grignard cross coupling of alkyl halides ${ }^{12}$, preparation of 1,2-azidoalcohols ${ }^{13}$, glycolysis of poly(ethylene terephthalate) ${ }^{14}$, "liquid fixed-bed" catalysts in flow application ${ }^{15}$, oxidative desulfurization of fuels ${ }^{16}$ and multi-component synthesis of 1 - and 5-substituted $1 \mathrm{H}$-tetrazoles ${ }^{17}$ and quinazoline derivatives ${ }^{18}$.

Recently, we introduced new sustainable synthetic methods using Fe-containing ionic liquids 19-21. In the present work we report the catalytic application of nanosized MCM-41 supported $n$ 1-butyl-3-methylimidazolium tetrachloroferrate(III), as catalyst in the synthesis of benzimidazole derivatives via condensation of different benzaldehydes and o-phenylenediamine.

\section{EXPERIMENTAL}

\section{General}

All compounds were purchased from Aldrich and Merck companies and used as received without further purification. The purity of the products and reaction monitoring were followed by thin layer chromatography on Merck DC-Alufolien plates pre-coated with silica gel $\mathrm{F}_{254}$. IR spectra were recorded on a Perkin-Elmer RX1 FTIR spectrometer. SEM images were obtained from a Philips XL30 instrument.

\section{Synthesis of MIL[bmim] $\left[\mathrm{FeCl}_{4}\right]$}

The magnetic ionic liquid was synthesized following the same way remarked in literature. 5 $\mathrm{mmol}[\mathrm{bmim}] \mathrm{Cl}(0.870 \mathrm{~g})$ and $5 \mathrm{mmol} \mathrm{FeCl}_{3}(0.825 \mathrm{~g})$ were added to a round bottom flask and stirred with a magnet for 15 minutes. The resulting ionic liquid was dissolved in ethyl acetate $(10 \mathrm{~mL})$ and the solution was centrifuged after filtration in order to separate any possible residue of inorganic salts. Afterwards, ethylacetate was evaporated and the obtained dark brown liquid, butyl methyl imidazolium tetrachloro ferrate(III) was dried under vacuum at $80 \stackrel{\circ}{\circ}$ overnight.

\section{Synthesis of MCM-41}

The source of silicon was tetraethyl orthosilicate (TEOS, 98\%). The structure-directing agent was cetyltrimethylammonium bromide (CTAB). A typical synthesis gel was prepared by adding $5.78 \mathrm{~g}$ of TEOS to an aqueous solution containing $1.01 \mathrm{~g}$ of CTAB and $0.34 \mathrm{~g}$ of $\mathrm{NaOH}$ and $30 \mathrm{ml}$ of deionized water. After further stirring for about $1 \mathrm{~h}$ at room temperature, the resulting homogeneous mixture was crystallized under static hydrothermal conditions at $383 \mathrm{~K}$ in a Teûon lined autoclave for $96 \mathrm{~h}$. The molar composition of the initial gel mixture was 1.0:0.10:0.30:60 TEOS/CTAB/NaOH/ $\mathrm{H}_{2} \mathrm{O}$. The solid product was obtained by ûltration, washed with deionized water, dried in air at $353 \mathrm{~K}$ and calcined in air at $813 \mathrm{~K}$ for $24 \mathrm{~h}$.

\section{The preparation of $[\mathrm{bmim}]\left[\mathrm{FeCl}_{4}\right] / \mathrm{MCM}-41$}

A suspensions of the MCM- $41(0.1 \mathrm{~g})$ and [bmim] $\left[\mathrm{FeCl}_{4}\right](1 \mathrm{mmol})$ in acetone $(5 \mathrm{mmol})$ were stirred vigorously for $12 \mathrm{~h}$. It was then centrifuged and the solid washed many times with acetone and then dried under vacuum at $40 \mathrm{C}$.

\section{General procedure for the synthesis of benzimidazoles in the presence of $[\mathrm{bmim}]\left[\mathrm{FeCl}_{4}\right]$ MCM-41(MIL/MCM-41)}

A mixture of 1.2 phenylenediamin $(1 \mathrm{mmol})$, aryl aldehyde (1 mmol), [bmim][FeCl $]$ /MCM-41 (0.05 gr) and ethanol $(5 \mathrm{~mL})$ was placed in a round bottom flask and refluxed for the given times recorded in Table 2. After completion of the reaction observed by TLC (using $n$-hexane/ ethylacetate (1:2) as eluent), the mixture was cooled to room temperature, the precipitate was filtered and washed with (hot ethanol) for several times. The resultant product purified by column chromatography and characterized by comparison of their physical data with benzimidazole derivatives reported in literature.

\section{RESULTS AND DISCUSSIONS}

First of all, FT IR spectroscopy and Scanning electron microscopy (SEM) were employed to confirm the successful immobilization of [bmim] $\left[\mathrm{FeCl}_{4}\right]$ onto the MCM-41. The FT IR spectrum and 
SEM image of $[\mathrm{bmim}]\left[\mathrm{FeCl}_{4}\right] / \mathrm{MCM}-41$ is shown in Fig. 1

In order to investigate the catalytic ability of the MIL/MCM-41, the condensation of 1-2 phenylenediamin with 4-nitrobenzaldehyde was chosen as the model reaction in different conditions. As seen in Table 1, the most appropriate condition among the candidate ones giving excellent yield in a proper time is the 8th process using ethanol as solvent under reflux condition.
Then, it was decided to evaluate the catalytic activity of the catalyst for the preparation of 2-Aryl Benzimidazoles and the results showed a highly effective performance of the catalyst (Scheme 1, Table 2).

With the optimal reaction conditions in hand, consisting of a 1:1 molar ratios of aldehyde and o-phenylenediamine with $0.05 \mathrm{~g}$ loading of [bmim] $\left[\mathrm{FeCl}_{4}\right] / \mathrm{MCM}-41$ and ethanol as solvent under reflux conditions, the generality and synthetic scope of this coupling protocol were demonstrated through the
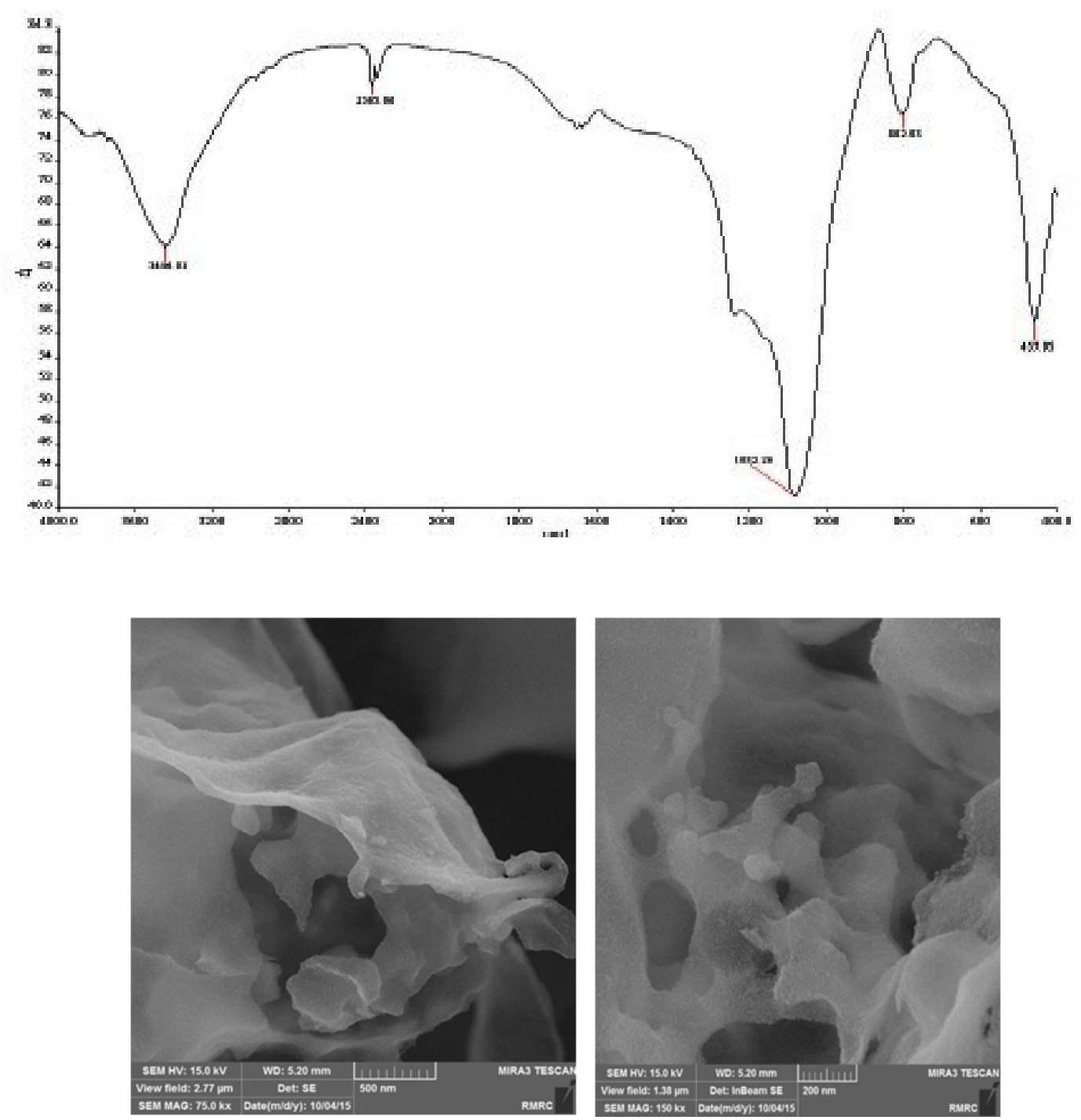

Fig. 1: The FT-IR spectrum (upper) and SEM image (lower) of [bmim] $\left[\mathrm{FeCl}_{4}\right] / \mathrm{MCM}-41$ 
synthesis of a series of 2-Aryl Benzimidazoles (Table 2). Pleasingly, a wide range of aromatic aldehydes with electron donating or electron withdrawing groups was well tolerated under the optimized reaction conditions. Also, postulated catalytic activity of the catalyst is shown (Scheme 2).

Table 1: The one-pot condensation reaction of 1-2 phenylenediamin (1 $\mathrm{mmol}$ ) and 4-nitrobenzaldehyde $(1 \mathrm{mmol})$ under different condition

\begin{tabular}{cccccc}
\hline Entry & $\begin{array}{c}\text { Catalyst } \\
(\mathbf{m m o l})\end{array}$ & Solvent & $\begin{array}{c}\text { Temperature } \\
(\mathbf{( - C )}\end{array}$ & $\begin{array}{c}\text { Time } \\
(\mathbf{m i n})\end{array}$ & Result \\
\hline 1 & 0.05 & - & 60 & 120 & No Reaction \\
2 & 0.05 & - & r.t & 120 & No Reaction \\
3 & 0.05 & $\mathrm{H}_{2} \mathrm{O}$ & reflux & 120 & No Reaction \\
4 & 0.05 & $\mathrm{n}-\mathrm{hexane}^{-}$ & reflux & 120 & Uncompleted \\
5 & 0.05 & $\mathrm{CHCl}_{3}$ & reflux & 120 & Uncompleted \\
6 & 0.05 & $\mathrm{CH}_{3} \mathrm{CN}$ & reflux & 120 & Uncompleted \\
7 & 0.02 & $\mathrm{EtOH}$ & reflux & 120 & Uncompleted \\
8 & 0.05 & $\mathrm{EtOH}$ & reflux & 30 & Completed \\
9 & 0.05 & $\mathrm{EtOH}$ & r.t & 120 & Uncompleted \\
\hline
\end{tabular}<smiles>[R]c1ccccc1-c1nc2ccccc2[nH]1</smiles>

Scheme 1: Synthesis of 2-Aryl Benzimidazoles

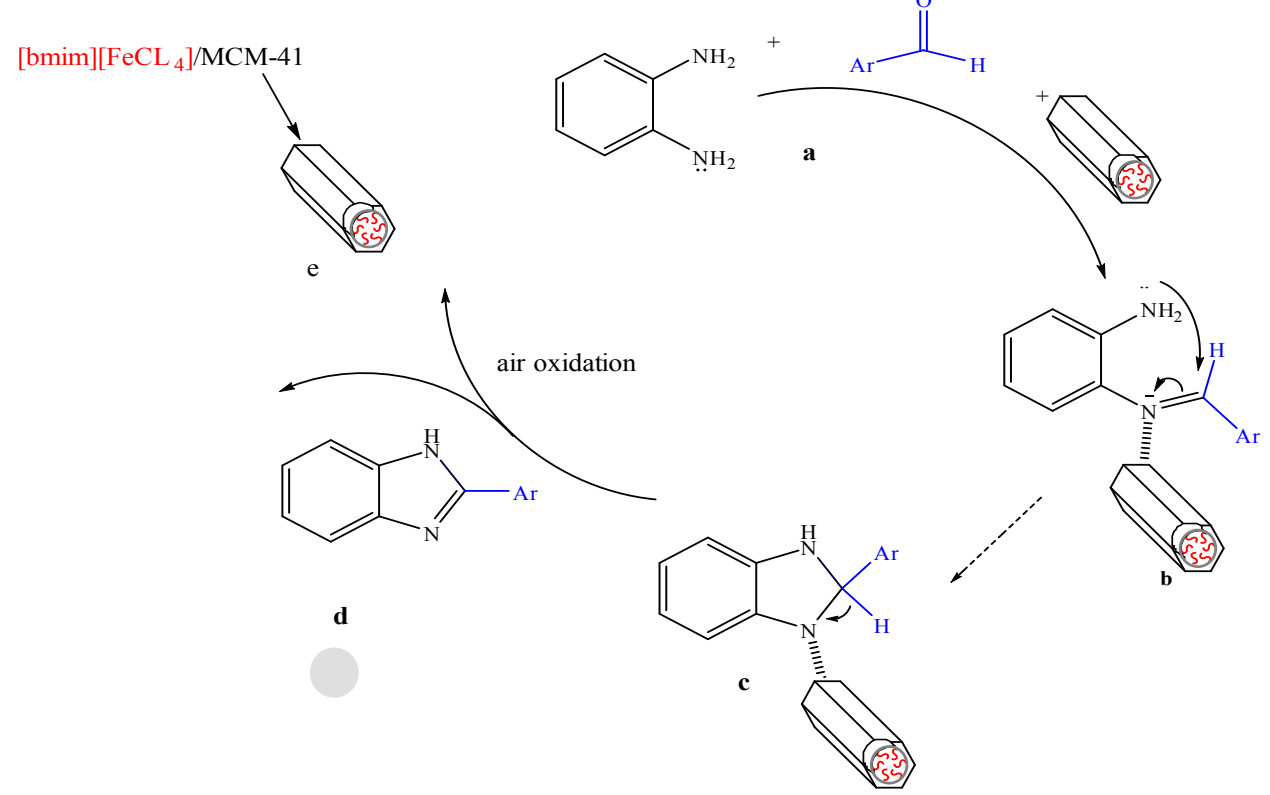

Scheme 2: Schematic illustration of the reaction 
Table 2: Synthesis of 2-Aryl Benzimidazoles and catalyzed by [bmim][FeCl4]/MCM-41 (MIL/MCM-41)

\begin{tabular}{|c|c|c|c|c|c|c|}
\hline Entry & Aldehyde & Product & Time (min) & Yield (\%) & M.p. (ㄷ) (Lit.) & Ref \\
\hline 1 & & & 70 & 75 & $\begin{array}{c}289-291 \\
(294-293)\end{array}$ & 22 \\
\hline 2 & & & 30 & 72 & $\begin{array}{c}290-288 \\
(292-290)\end{array}$ & 24 \\
\hline 3 & & & 55 & 74 & $\begin{array}{c}263-261 \\
(263.5-(261.5\end{array}$ & 23 \\
\hline 4 & & & 30 & 83 & $\begin{array}{c}319-317 \\
(320-318)\end{array}$ & 22 \\
\hline 5 & Сно & & 60 & 72 & $\begin{array}{c}260-258 \\
(262-260)\end{array}$ & 22 \\
\hline 6 & СHO & & 40 & 75 & $\begin{array}{c}178-176 \\
(182-180)\end{array}$ & 24 \\
\hline 7 & ОМе & & 40 & 73 & $\begin{array}{c}235-232 \\
(233-231)\end{array}$ & 23 \\
\hline 8 & & & 75 & 81 & $295-290$ & \\
\hline & & & & & $242-240$ & \\
\hline 9 & & & 45 & 70 & -248 & 24 \\
\hline
\end{tabular}




\section{CONCLUSION}

We have developed a facile and environmentally friendly protocol for the syntheses of 2-Aryl Benzimidazoles derivatives in the presence of [bmim $]\left[\mathrm{FeCl}_{4}\right] / \mathrm{MCM}-41$ as a novel environmentally safe heterogeneous catalyst. This method offers several advantages including easy workup, green condition, good yield and simple purification.

\section{ACKNOWLEDGMENTS}

We are sincerely grateful to the Omidiyeh Branch, Islamic Azad University for the financial support of this project.

\section{REFERENCES}

1. Tang,F.; Li,L.; Chen,D.Adv. Mater. 2012, 24, 1504-1534.

2. Juan, J.C.; Zhang, J.C .; Yarmo, M.A. J. M. Catal A: Chem. 2007, 265-267

3. Hayashi, S.; Hamaguchi, H.O. Chem. Lett.2004, 33, 1590-1591.

4. Aswathy, J.; Gawe ${ }^{3},-$;Vibin Ipe,T.; P. Radhakrishnan, N.; Padmanabhan,A.S.; Suresh,M. J. Mol. Liq. 2016, 21 ,319-331. Li, M.; De Rooy, S. L.; Bwambok, D. K.; ElZahab, B.; DiTusa, J. F.; Warner, I. M. Chem. Commun. 2009, 6922-6924.

6. Krieger, B.M.; Lee, H.Y.; Emge, T.J. ; Wishart, J.F. ; Castner, J.E.W. Phys. Chem. Chem. Phys. 2010, $12,8919$.

7. Del Sesto, R.E. ; McCleskey, T.M. ; Burrell, A.K. ; Baker, G.A. ; Thompson, J.D. ; Scott, B.L. ; Wilkes, J.S.; Williams, P. Chem. Commun. 2008, 447.

8. Yoshida, Y.; Saito, G. Phys. Chem. Chem. Phys. 2010, 12, 1675.

9. Branco, A. ; Branco, L.C. ; Pina, F. Chem. Commun.2011,47, 2300.

10. Brown, P. ; Butts, C.P. ; Eastoe, J.; Padron Hernandez, E.; Machado, F.L.D.A.; De Oliveira, R.J.Chem. Commun. 2013, 49, 2765.

11. Valkenberg, M. H.; deCastro, C.; Hölderich,W. F. Appl. Catal., A. 2001, 215, 185-190.
12. Bica, K.; Gaertner, P. Org. Lett. 2006, 8, 733735.

13. Godajdar, B. M.; Kiasat, A. R.; Hashemi, M. M.J. Mol. Liq. 2013, 183, 14-19.

14. Wang, H.; Yan, R.; Li, Z.; Zhang, X.; Zhang, S. Catal. Commun. 2010, 11, 763-767.

15. Misuk, V.; Breuch, D.; Löwe, H. Chem. Eng. J .2011, 173 , 536-540.

16. Zhu, W.; Wu, P.; Yang, L.; Chang, Y.; Chao, Y.; Li, H.; Jiang, Y.; Jiang, W.; Xun, S. Chem. Eng. J . 2013, 229, 250-256

17. Khalafi-Nezhad, A.; Mohammadi, S. RSC Adv. 2013, 3 , 4362-4371.

18. Panja, S.K.; Saha, S. RSC Adv. 2013 , 3 ,14495-14500.

19. Sayyahi,S.; Azin,A.; Saghanezhad, S. J. J. Mol. Liq. 2014, 198,30-36

20. Sayyahi,S.; Shabani,S.; Ghasemi,S.; Azin,A.;Hasani, S. M. Orient. J. Chem.2015, 31,1773-1778

21. Khodajoo, M.; Sayyahi,S.; Saghanezhad, S.J. Russ. J. Gen. Chem., 2016, 86, 1177-1181.

22. Bahrami, K.; Khodaei, M. M.; Nejati, A. Green Chem. 2010, 12 , 1237-1241

23. Gadekar, L. S.; Arbad, B. R.; Lande, M. K. Chin. Chem. Lett . 2010, 21 , 1053-1056.

24. Teimouri, A.; Chermahini, A. N.; Salavati, H.; Ghorbanian, L. J. Mol. Catal. A: Chem . 2013, $373,38-45$ 